\title{
Effect of Conventional Versus Passive Self-Ligating Vestibular Appliances on Torque, Tip and Transverse Dental Changes in Patients Affected by Class I Malocclusion: A Retrospective Study
}

\author{
Mario Palone ${ }^{1}$, Pietro Panzeri², Francesca Cremonini1 ${ }^{\circledR}$, Giorgio Alfredo Spedicato ${ }^{3}\left({ }^{\circledR}\right.$, Virginia \\ Squarci ${ }^{4}$, Paolo Albertini ${ }^{1}$ (D)
}

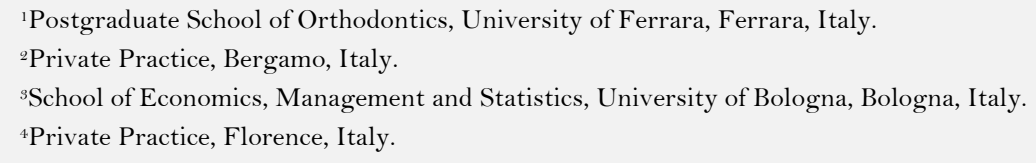

Correspondence: Mario Palone, Postgraduate School of Orthodontics, University of Ferrara, Via Luigi Borsari 46, Ferrara 44121, Italy. E-mail: mario.palone88@,gmail.com

Academic Editor: Alessandro Leite Cavalcanti

Received: 29 January 2021 / Review: 25 March 2021 / Accepted: 28 March 2021

How to cite: Palone M. Panzeri P. Cremonini F. Spedicato GA. Squarci V. Albertini P. Effect of conventional versus passive self-ligating vestibular appliances on torque, tip and transverse dental changes in patients affected by class I malocclusion: a retrospective study. Pesqui Bras Odontopediatria Clín Integr. 2021; 21 (supp1):e0031. https://doi.org/10.1590/pboci.2021.106

\begin{abstract}
Objective: To evaluate the effects of passive self-ligating appliances (PSLAs) and conventional ligating appliances (CLAs) during orthodontic treatment regarding torque, tip, and transversal dental changes. Material and Methods: Dental parameters were digitally acquired from pre- and post-treatment models of each subject belonging to two groups of patients treated with PSLAs (23 patients; 11 females and 12 males with a mean age of $14.2 \pm 1.6$ years) and CLAs (18 patients; 10 females and 8 males with a mean age of 14.3 \pm 1.9 years), respectively. All subjects had Class I or slight Class II malocclusion $(\leq 2 \mathrm{~mm})$, permanent dentition and no previous orthodontic treatment. After normality of data was assumed, a paired sample ttest rejected any side differences at To and, therefore, the data were grouped by tooth group. Statistical analyses were performed using a linear mixed-effect framework, assuming the appliance, time, and interactions as fixed effects and the tooth type as random effects. Finally, post-hoc effect analysis was used to contrast modeled marginal effects $(\mathrm{p}<0.05)$. Results: For both appliances, there is a general increase of both torque and transverse values at T1, especially for PSLAs. Tip shows a general reduction in the lateral sectors for both appliances is registered. The only significant statistical difference referred to appliances' efficacy is located to mandibular intermolar width. Conclusion: Both appliances have an expansive potential for both torque and transverse dental changes. No evident differences are detectable between appliances except for the rate of the mandibular intermolar width increase.
\end{abstract}

Keywords: Orthodontics; Malocclusion, Angle Class I; Torsion, Mechanical; Orthodontic Brackets. 


\section{Introduction}

The advent of self-ligating brackets increased success in Orthodontics, with an immediate hypothesis of several clinical improvements than conventional brackets [1]. Initially, at their lunch, companies and supporters asserted that they are more efficient and effective in treating malocclusions than conventional brackets [1,2]. In fact, low friction should facilitate alignment, increase appointment intervals and reduce the overall treatment time $[3,4]$.

The initial hypothesis about lower friction is that teeth could be moved with more biological forces concerning conventional ligating appliances (CLAs) favoring alveolar bone generation [5-7], greater amounts of bodily lateral expansion, better sliding mechanics, less proclination of anterior teeth [8,9], reducing of overall treatment time and less need for extractions with self-ligating brackets [10,11].

However, there is poor evidence in the literature regarding the overall reduction of friction with selfligating brackets. As stated by a systematic review, self-ligating brackets seem to produce less friction with small size and round $\mathrm{NiTi}$ archwires in an ideally aligned arch with the absence of tipping and torque active force expression. These advantages get lost when larger rectangular archwires are used and when archwires work in misaligned arches, which are the rule in clinical conditions [12].

A meta-analysis regarding intercanine and intermolar widths showed no significant differences between them [13], although some authors observed greater increases in intermolar widths with self-ligating brackets [14,15]. According to literature, only less mandibular incisor proclination and less working chair-side time have been demonstrated for conventional bracket, whereas other advantages claimed like major efficiency and efficacy, less pain, reduced plaque accumulation, greater amounts of lateral expansion, fewer clinical appointments and major outcome stability have not been demonstrated [13,16].

As a matter of fact, Anand et al. pointed out heterogenous results between self-ligating appliances (SLAs) and CLAs when different clinicians are investigated [17]. Fleming et al. [14] stated that the efficacy and efficiency of the orthodontic treatment seem to be mostly influenced by operator 'skills rather than the type of appliances used. On the other hand, the clinician should decide if the reduced chair time and less care are needed to counterbalance the higher costs of self-ligating brackets [14].

If transverse and sagittal aspects of dental arches have been previously investigated [18,19], a direct comparison concerning some dental parameters (tip and torque values) expressed by such appliances has not. The variations in torque and tip can be due to many factors, such as bracket design, play between the slot and the wire, slot and wire dimension, ligature mode, wire stiffness and torsion magnitude [20-22].

The purpose of this retrospective study was to compare torque, tip and transverse dental changes during orthodontic treatment with both passive self-ligating (PSLAs) and vestibular CLAs through digital analysis of dental arches. The null hypothesis is that there are no differences among the groups investigated.

\section{Material and Methods}

\section{Study Design, Ethical Clearance and Sample}

This retrospective study has been approved by Ethical Committee of the Department of Orthodontics of the University of Ferrara, with protocol n. 4/2017. A total of 41 patients, treated respectively with PSLAs and CLAs, were treated by two different orthodontists experienced in their use and both members of the European Board of Orthodontics. Both clinicians have been chosen due to their similar experience and skill in orthodontics according to each type of vestibular appliance used. 
Subjects were retrospectively analyzed according to the following inclusion criteria: patients with at least 13 years of age at the start of the treatment and a natural permanent dentition although the total lack or poor eruption of second molars could be accepted; Class I or mild Class II dental molar relationship (-2 mm) (considering the distance between mesio-buccal cusp of maxillary first molar and mesio-buccal sulcus of mandibular first molar) [23] and overjet $\leq 3 \mathrm{~mm}$, with the eventuality of using Class II elastics no more than 3 months; slight or moderate maxillary and mandibular crowding (<4-5 mm) without any previous fixed orthodontic extractive, whereas previous orthopedic treatment could be accepted; no severe rotations beyond $30^{\circ}$; absence of sucking habits, craniofacial syndromes, cysts, cleft lip or palate, and multiple or advanced caries. Exclusion criteria were: Class III tendency or full Class III malocclusions, Class II head-to-head (4 mm) and Class II full cusp malocclusion [23], prosthetic rehabilitation and those patients who need corrective jaw surgery or with incomplete records.

Group I included 23 patients ( 11 female and 12 male) with a mean age of $14.2 \pm 1.6$ years at the start of the treatment. In Group I, patients were treated in both arches with a passive self-ligating bracket with standard values for tip and torque and 0.022-inch slots (Damon Q, Ormco Corp., Glendora, CA, USA). The treatment consisted of a standard archwire sequence: 0.014-inch round, followed by a 0.014 x 0.025-inch rectangular, a 0.018 x 0.025-inch rectangular copper nickel-titanium alloy, and a 0.019 x 0.025 -inch stainless steel archwire (Ormco Corp., Glendora, CA, USA).

Group II included 18 patients (10 female and 8 male) with a mean age of $14.3 \pm 1.9$ years at the start of the treatment. The patients in Group II were treated in both arches with a conventional fixed multibracket appliance and 0.022-inch slots (Sweden \& Martina, Due Carrare, Padua, Italy). The treatments consisted of the following archwire sequence: a 0.016-inch round copper nickel-titanium, a 0.019 x 0.025-inch round copper nickel-titanium and a 0.019 x 0.025-inch stainless steel archwire.

For every patient, maxillary and mandibular dental casts were collected before treatment (To) and immediately after treatment (T1). A total of 82 dental casts were scanned with an intraoral scanner (CS 3600 , Carestream Dental LLC, Atlanta, USA), exported in an .STL file and associated with a reference number to protect their identity and blind them to the operator who performed measurements.

A total of 100 anatomical reference points per model were identified by a single expert operator (PA), including second molars, using VAM software (Vectra; Canfield Scientific, Fairfield, NJ, USA) according to the method proposed and validated by Huanca Ghislanzoni [24].

Therefore, their three-dimensional coordinates were exported into specific .txt files (Microsoft Excel, Microsoft, Redmond, WA, USA). This enabled extrapolation through a complex algorithm of the tip and torque values (Figure 1) of each tooth with respect to an occlusal reference plane passing through the following points: 1) The mesiovestibular cusp on the right first molar (Point A); 2) The mesiovestibular cusp on the left first molar (Point B); and 3) The centroid of all the most occlusal points on the FACC line (the facial axial of the clinical crown) of the all teeth, excluding the cusp of the canines and the second molar (Figure 2).

Thus, six points were assigned to the incisors and canines, respectively, and eight points were assigned to each of the premolars and molars (Figure 3). Moreover, linear transverse diameters were measured from cusps of canine and first molars obtaining intercanine and intermolar widths for both arches.

After six weeks, measurements on 18 randomized models were repeated by the same operator (PA), and the method error $(\mathrm{ME})$ was calculated according to Dahlberg's formula $\left(\mathrm{S} 2=\sum \mathrm{d} 2 / 2 \mathrm{n}\right)$ [25]. Dahlberg values ranged between $0.11^{\circ}$ and $26.50^{\circ}$ for angular values and between $0.064 \mathrm{~mm}$ and $3.19 \mathrm{~mm}$ for linear measurements. The systematic error was calculated via the dependent Student's t-test, with a p-value of $<0.05$ 
being considered as significant. The mean p-value was 0.462 and no statistically significant differences were found in any case.

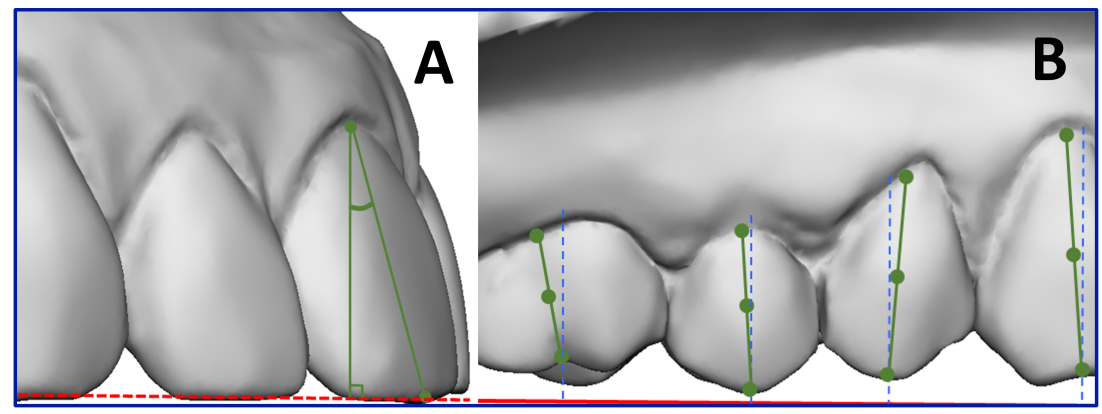

Figure 1. Graphical representation of torque (A), tip (B) measurements.

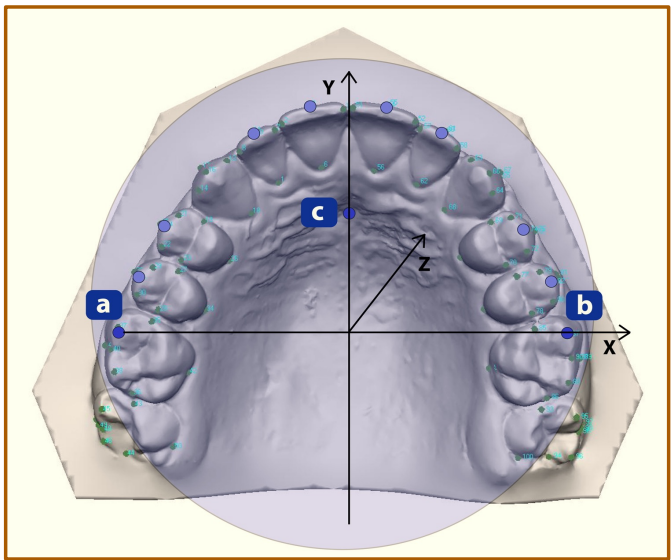

Figure 2. 3D view of occlusal plane used as a reference for all measurements.

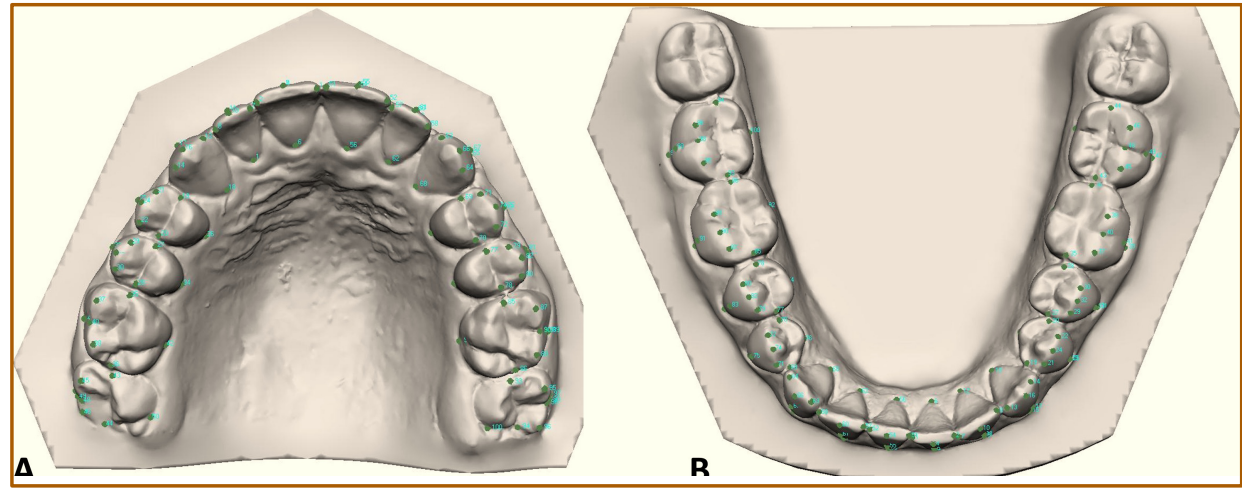

Figure 3. One hundred anatomical reference points in maxilla (A) and in mandible (B), respectively.

Statistical Analysis

Statistical analyses were performed using the $\mathrm{R}$ software ( $\mathrm{R}$ Core Team 2019) and a statistical significance threshold of $5 \%$. A preliminary analysis of normality was performed using the Shapiro-Wilk test for each measurement performed, and the assumption of normality is well supported by our data. Normality was rejected in only 9 cases for torque measurements and in 7 cases for tip measurements when a threshold pvalue of $<0.05$ was used. 
Statistical analysis was performed to investigate if any difference both angular measurements (tip and torque) are present between the right and left sides for both arches at To. First of all, a paired sample t-test, with a significance threshold of $\alpha=0.05(5 \%)$, was performed on the digitally acquired data. No significant differences between right and left side were detected in either sample; therefore, angular measurements were grouped for analogous teeth. This grouping process has allowed duplicating the number of observations analysed for each tooth. After this, the between groups homogeneity at To has been investigated through a two-sample t-test, considering a p-value $<0.05$ as significant for both dental parameters investigated and gender distribution.

Statistical analyses between groups and the effect of time were studied using a linear mixed effect framework with the lme4 $\mathrm{R}$ package assuming the operator and time as a fixed effect and the patient-side as random effects. Finally, post-hoc effect analysis was used to contrast modeled marginal effects differences using the $\mathrm{R}$ emmeans library. The given sample size leads to an estimated effect size equal to $\mathrm{f}=0.24$, which indicates that the experiments are able to detect a medium effect size according to the thresholds given by the two groups [26].

\section{Results}

Homogeneity among groups has been found for both gender distribution and all angular measurements, except for the maxillary first premolars for tip and mandibular lateral incisors for torque. Homogeneity for intercanine and intermolar width has been respected in any case. Despite these little differences for the angular measures, both groups could be considered homogeneous with each other.

Descriptive analysis for pre-, post-treatment and delta values of angular (torque and tip) and linear measurements (intercanine and intermolar width for both arches) are reported in Tables 1 and 2 , respectively.

Table 1. Torque and tip values at To and $\mathrm{T} 1$ and their respective variation during treatment $(\Delta)$ for both group 1 (treated with self-ligating appliances) and group 2 (treated with conventional appliances).

\begin{tabular}{|c|c|c|c|c|c|c|c|c|c|c|c|}
\hline \multirow{3}{*}{ Teeth } & \multirow{3}{*}{ Group } & \multicolumn{5}{|c|}{ Torque } & \multicolumn{5}{|c|}{ Tip } \\
\hline & & \multicolumn{2}{|c|}{ Initial (To) } & \multicolumn{2}{|c|}{ Final (T1) } & \multirow{2}{*}{$\begin{array}{l}\Delta\left(\mathrm{T}_{1-\mathrm{To}}\right) \\
\text { Value }\left(^{\circ}\right)\end{array}$} & \multicolumn{2}{|c|}{ Initial (To) } & \multicolumn{2}{|c|}{ Final (T1) } & \multirow{2}{*}{$\begin{array}{c}\Delta\left(\mathrm{T}_{1-\mathrm{TO}}\right) \\
\text { Value }\left(^{\circ}\right)\end{array}$} \\
\hline & & Mean $\left({ }^{\circ}\right)$ & $\operatorname{SD}\left({ }^{\circ}\right)$ & Mean $\left(^{\circ}\right)$ & $\operatorname{SD}\left({ }^{\circ}\right)$ & & Mean $\left(^{\circ}\right)$ & $\operatorname{SD}\left({ }^{\circ}\right)$ & Mean $\left(^{\circ}\right)$ & $\operatorname{SD}\left(^{\circ}\right)$ & \\
\hline \multirow{2}{*}{$\mathrm{U}_{1}$} & 1 & 3.38 & 4.69 & 4.82 & 4 & 1.44 & 5.88 & 5.88 & 4.77 & 2.95 & -1.11 \\
\hline & 2 & 4.22 & 7.42 & 5.25 & 4.59 & 1.03 & 3.58 & 3.58 & 3.02 & 1.07 & -0.56 \\
\hline \multirow{2}{*}{$\mathrm{U}_{2}$} & 1 & -0.5 & 7.28 & 3.74 & 4.28 & 4.24 & 6.96 & 6.96 & 7 & 3.54 & 0.04 \\
\hline & 2 & 2.55 & 5.59 & 3.88 & 3.24 & 1.33 & 4.74 & 7.9 & 7.26 & 1.6 & 2.52 \\
\hline \multirow{2}{*}{ U3 } & 1 & -4.44 & 8.25 & -2.17 & 3.82 & 2.27 & 6.94 & 6.94 & 4.48 & 6.61 & -2.46 \\
\hline & 2 & -4.68 & 7.63 & -3.6 & 5.1 & 1.08 & 6.89 & 8.74 & 7.66 & 0.86 & 0.77 \\
\hline \multirow{2}{*}{$\mathrm{U} 4$} & 1 & -9.83 & 4.7 & -4.56 & 5.36 & 5.27 & 1.21 & 7.9 & 0.84 & 5.31 & -0.37 \\
\hline & 2 & -11.55 & 4.5 & -7.45 & 4 & 4.1 & 7.97 & 6.88 & 2.5 & 0.87 & -5.47 \\
\hline \multirow{2}{*}{$\mathrm{U} 5$} & 1 & -13.88 & 6.82 & -7.91 & 4.95 & 5.97 & 4.67 & 6.11 & 3.09 & 4.9 & -1.58 \\
\hline & 2 & -14.49 & 8.55 & -7.42 & 4.06 & 7.07 & 6.67 & 7.07 & 2.68 & 1.09 & -3.99 \\
\hline \multirow{2}{*}{ U6 } & 1 & -13.57 & 7.25 & -11.64 & 5.48 & 1.93 & 1.42 & 7.83 & 0.55 & 6.47 & -0.87 \\
\hline & 2 & -15.7 & 8.86 & -11.7 & 3.32 & 4 & 5.18 & 8.25 & 4.83 & 0.87 & -0.35 \\
\hline \multirow{2}{*}{$\mathrm{U} 7$} & 1 & -17.67 & 9.33 & -9.74 & 8.5 & 7.93 & -9.27 & 14.76 & -3.46 & 6.36 & 5.81 \\
\hline & 2 & -11.15 & 19.01 & -9.89 & 3.45 & 1.26 & -3.13 & 17.9 & 1.13 & 2.45 & 4.26 \\
\hline \multirow{2}{*}{$\mathrm{L}_{1}$} & 1 & -5.04 & 5.42 & -0.17 & 5.12 & 4.87 & -0.09 & 5.04 & 0.17 & 2.44 & 0.26 \\
\hline & 2 & -2.51 & 6.31 & 0.27 & 4.18 & 2.78 & 4.19 & 2.77 & 0.22 & 1.5 & -3.97 \\
\hline $\mathrm{L} 2$ & 1 & -11.68 & 4.95 & -2.22 & 4.01 & 8.46 & -3.4 & 4.85 & 0.76 & 3.61 & 4.16 \\
\hline
\end{tabular}




\begin{tabular}{|c|c|c|c|c|c|c|c|c|c|c|c|}
\hline & 2 & -6.53 & 7.4 & -2.42 & 3.88 & 4.11 & -2.59 & 6.79 & 0.25 & 1.7 & 2.84 \\
\hline \multirow{2}{*}{ L3 } & 1 & -14.54 & 5.06 & -8.85 & 4.39 & 5.69 & -0.65 & 7.66 & 2.91 & 5.47 & 3.56 \\
\hline & 2 & -7.29 & 7.13 & -9.84 & 4.02 & -2.55 & 3.98 & 6.08 & 2.24 & 2.07 & -1.74 \\
\hline \multirow{2}{*}{$\mathrm{L}_{4}$} & 1 & -22.96 & 5.65 & -15.98 & 4.2 & 6.98 & 3.3 & 4.71 & 0.63 & 5.32 & -2.67 \\
\hline & 2 & -18.88 & 6.32 & -16.52 & 3.06 & 2.36 & 3.54 & 6.61 & 0.81 & 2.46 & -2.73 \\
\hline \multirow{2}{*}{$\mathrm{L} 5$} & 1 & -27.93 & 5.91 & -22.28 & 4.26 & 5.65 & 6.46 & 7.45 & 3.26 & 5.24 & -3.2 \\
\hline & 2 & -28.07 & 9.22 & -21.93 & 4 & 6.14 & 7.45 & 4.67 & 1.58 & 2.49 & -5.87 \\
\hline \multirow{2}{*}{ L6 } & 1 & -37.41 & 4.25 & -37.74 & 5.71 & -0.33 & 4.97 & 6.53 & -1.24 & 5.08 & -6.21 \\
\hline & 2 & -35.93 & 9.22 & -32.56 & 5.14 & 3.37 & 7.32 & 7.82 & 1.44 & 1.59 & -5.88 \\
\hline \multirow{2}{*}{$\mathrm{L} 7$} & 1 & -47.68 & 9.1 & -37.95 & 9.01 & 9.73 & 2.23 & 9.59 & -2.99 & 6.84 & -5.22 \\
\hline & 2 & -38.03 & 8.67 & -37.11 & 5.14 & 0.92 & 6.56 & 9.78 & 3 & 2.6 & -3.56 \\
\hline
\end{tabular}

U=Maxillary; L=Mandibular; 1=Central Incisor; 2=Lateral Incisor; 3=Canine; 4=First Premolar; $5=$ Second Premolar; 6=First Molar; $7=$ Second Molar.

Table 2. Transverse measures for intercanine and intermolar width for both arches and their respective variation during treatment $(\Delta)$.

\begin{tabular}{|c|c|c|c|c|c|c|c|c|c|c|c|}
\hline \multirow{3}{*}{ Group } & \multirow{3}{*}{ Arches } & \multicolumn{5}{|c|}{ Intercanine Width } & \multicolumn{5}{|c|}{ Intermolar Width } \\
\hline & & \multicolumn{2}{|c|}{ Initial (To) } & \multicolumn{2}{|c|}{ Final ( $\mathrm{T} 1)$} & \multirow{2}{*}{$\begin{array}{c}\Delta \\
(\mathrm{To}-\mathrm{T} 1) \\
\text { Value }\end{array}$} & \multicolumn{2}{|c|}{ Initial (To) } & \multicolumn{2}{|c|}{ Final (T1) } & \multirow{2}{*}{$\begin{array}{c}\Delta \\
\text { (To-T1 } \\
\text { Value }\end{array}$} \\
\hline & & Mean & $\mathrm{SD}$ & Mean & $\mathrm{SD}$ & & Mean & $\mathrm{SD}$ & Mean & $\mathrm{SD}$ & \\
\hline 1 & Maxillary & 33.03 & 2.23 & 35.99 & 1.77 & 2.96 & 49.97 & 1.58 & 52.37 & 1.55 & 2.40 \\
\hline 2 & & 32.91 & 2.65 & 35.16 & 0.94 & 2.25 & 50.12 & 2.97 & 52.66 & 1.1 & 2.54 \\
\hline 1 & Mandibular & 26.06 & 1.59 & 27.4 & 1.05 & 1.34 & 43.24 & 1.84 & 45.65 & 0.9 & 2.41 \\
\hline 2 & & 25.91 & 2.12 & 26.67 & 1.16 & 0.76 & 41.23 & 2.6 & 41.84 & 2.01 & 0.61 \\
\hline
\end{tabular}

*Values in $\mathrm{mm}$.

About torque changes, there is a general increase during the treatment for both groups, except for mandibular canines and first molars in Group 2, where a certain torque reduction has been observed, albeit minimal.

About tip changes, a common trend could not be observed with variations ranging from $-6.21^{\circ}$ (mandibular first molars in Group 1) to $5.81^{\circ}$ (maxillary second molar in Group 1); nevertheless, a general tendency towards a reduction of tip values in the posterior sectors could be observed, except for the maxillary second molars, which registered the opposite in both groups.

Regarding transverse changes, there is always an increase of intercanine and intermolar width for both arches, ranging from $0.61 \mathrm{~mm}$ (mandibular intermolar width in Group 2) to $2.96 \mathrm{~mm}$ (maxillary intercanine width in Group 1).

After, a statistical comparison analysis has been performed to locate what variations during the orthodontic treatment reach the statistical significance $(\mathrm{p}<0.05)$. It was reached in almost all angular measurements except in eight pair comparisons for the torque and ten pair comparisons for the tip (Table 3 ).

All the variation in intercanine and intermolar width registered a statistically significant augmentation, except for mandibular intermolar width variation in Group 2 (Table 4). Further statistical comparison of variations during treatment between groups locate a significant difference only in four statistical couplings: two for torque (mandibular lateral incisors and mandibular first premolars) with a major variation detected in Group 1 and two for tip (maxillary first premolars and mandibular canines) with a major tendency to a reduction in Group 2. 
Table 3. Statistical comparisons for torque and tip angular values changes for both arches from pre- (To) to post-treatment values (T1).

\begin{tabular}{|c|c|c|c|c|c|c|c|c|c|c|c|c|c|c|c|}
\hline \multirow[t]{2}{*}{ Teeth } & \multirow[t]{2}{*}{ Group } & \multicolumn{7}{|c|}{ Torque } & \multicolumn{7}{|c|}{ Tip } \\
\hline & & Estimate & $\mathrm{SE}$ & Df & Lower.CL & Upper.CL & T.ratio & $\mathrm{p}$-value & Estimate & $\mathrm{SE}$ & Df & Lower.CL & Upper.CL & T.ratio & $\mathrm{p}$-value \\
\hline \multirow{2}{*}{$\mathrm{U}_{1}$} & 1 & -1.41 & 1.11 & 125.16 & -3.61 & 0.80 & -1.26 & 0.21 & 1.16 & 1.01 & 122.42 & -0.85 & 3.16 & 1.14 & 0.26 \\
\hline & 2 & -1.02 & 0.98 & 124.42 & -2.97 & 0.93 & -1.04 & 0.30 & 0.58 & 0.90 & 122.87 & -1.21 & 2.37 & 0.64 & 0.52 \\
\hline \multirow{2}{*}{$\mathrm{U} 2$} & 1 & -4.06 & 1.03 & 97.62 & -6.10 & -2.02 & -3.94 & $0.00^{*}$ & 0.05 & 1.24 & 119.25 & -2.40 & 2.50 & 0.04 & 0.97 \\
\hline & 2 & -1.18 & 0.93 & 98.07 & -3.03 & 0.67 & -1.27 & 0.21 & -2.65 & 1.13 & 120.91 & -4.88 & -0.42 & -2.35 & $0.02 *$ \\
\hline \multirow{2}{*}{ U3 } & 1 & -2.60 & 1.36 & 116.70 & -5.29 & 0.09 & -1.92 & 0.06 & 2.46 & 1.69 & 113.83 & -0.88 & 5.81 & 1.46 & 0.15 \\
\hline & 2 & -1.19 & 1.28 & 119.91 & -3.72 & 1.33 & -0.94 & 0.35 & -0.77 & 1.64 & 127.27 & -4.01 & 2.47 & -0.47 & 0.64 \\
\hline \multirow{2}{*}{$\mathrm{U} 4$} & 1 & -5.58 & 0.99 & 96.40 & -7.54 & -3.62 & -5.66 & $0.00^{*}$ & 0.37 & 1.19 & 121.65 & -1.98 & 2.72 & 0.31 & 0.76 \\
\hline & 2 & -4.05 & 0.88 & 97.89 & -5.79 & -2.31 & -4.63 & $0.00^{*}$ & 5.76 & 1.13 & 126.66 & 3.53 & 8.00 & 5.10 & $0.00^{*}$ \\
\hline \multirow{2}{*}{ U5 } & 1 & -5.94 & 1.38 & 115.39 & -8.68 & -3.20 & -4.29 & $0.00^{*}$ & 1.60 & 1.07 & 111.05 & -0.53 & 3.73 & 1.49 & 0.14 \\
\hline & 2 & -6.78 & 1.35 & 121.99 & -9.46 & -4.10 & -5.01 & $0.00^{*}$ & 4.09 & 1.07 & 121.79 & 1.96 & 6.21 & 3.81 & $0.00^{*}$ \\
\hline \multirow{2}{*}{ U6 } & 1 & -1.88 & 1.29 & 124.66 & -4.44 & 0.68 & -1.45 & 0.15 & 0.86 & 1.38 & 118.22 & -1.87 & 3.60 & 0.63 & 0.53 \\
\hline & 2 & -3.67 & 1.19 & 125.88 & -6.01 & -1.32 & -3.09 & $0.00^{*}$ & 0.26 & 1.32 & 121.62 & -2.35 & 2.87 & 0.20 & 0.84 \\
\hline \multirow{2}{*}{$\mathrm{U} 7$} & 1 & -7.84 & 2.89 & 101.35 & -13.57 & -2.10 & -2.71 & $0.01^{*}$ & -5.61 & 2.99 & 120.87 & -11.53 & 0.30 & -1.88 & 0.06 \\
\hline & 2 & -1.06 & 2.61 & 105.63 & -6.25 & 4.12 & -0.41 & 0.68 & -4.54 & 2.53 & 116.35 & -9.56 & 0.47 & -1.80 & 0.08 \\
\hline \multirow{2}{*}{$\mathrm{L}_{1}$} & 1 & -4.87 & 0.93 & 120.16 & -6.71 & -3.03 & -5.24 & $0.00^{*}$ & -0.27 & 3.67 & 125.08 & -7.52 & 6.98 & -0.07 & 0.94 \\
\hline & 2 & -2.69 & 0.85 & 122.54 & -4.38 & -1.01 & -3.17 & $0.00^{*}$ & 3.97 & 3.22 & 128.59 & -2.39 & 10.33 & 1.23 & 0.22 \\
\hline \multirow{2}{*}{$\mathrm{L} 2$} & 1 & -9.46 & 0.99 & 118.35 & -11.43 & -7.49 & -9.52 & $0.00^{*}$ & -4.16 & 1.12 & 118.34 & -6.38 & -1.94 & -3.71 & $0.00^{*}$ \\
\hline & 2 & -4.02 & 0.91 & 120.00 & -5.83 & -2.21 & -4.39 & $0.00^{*}$ & -2.81 & 1.01 & 123.76 & -4.80 & -0.81 & -2.78 & $0.01 *$ \\
\hline \multirow{2}{*}{$\mathrm{L} 3$} & 1 & -5.69 & 1.11 & 118.03 & -7.89 & -3.48 & -5.11 & $0.00^{*}$ & -3.57 & 1.21 & 119.48 & -5.97 & -1.17 & -2.95 & $0.00^{*}$ \\
\hline & 2 & -3.49 & 1.11 & 125.96 & -5.68 & -1.30 & -3.15 & $0.00^{*}$ & 1.78 & 1.19 & 128.79 & -0.57 & 4.13 & 1.50 & 0.14 \\
\hline \multirow{2}{*}{$\mathrm{L} 4$} & 1 & -6.98 & 1.12 & 108.73 & -9.21 & -4.75 & -6.21 & $0.00^{*}$ & 2.55 & 1.13 & 91.28 & 0.31 & 4.79 & 2.26 & $0.03 *$ \\
\hline & 2 & -2.44 & 1.16 & 124.34 & -4.74 & -0.15 & -2.11 & $0.04^{*}$ & 2.74 & 1.05 & 95.84 & 0.65 & 4.83 & 2.60 & $0.01 *$ \\
\hline \multirow{2}{*}{ L5 } & 1 & -5.58 & 1.33 & 112.29 & -8.21 & -2.95 & -4.21 & $0.00^{*}$ & 3.19 & 1.23 & 119.98 & 0.76 & 5.62 & 2.60 & $0.01 *$ \\
\hline & 2 & -6.04 & 1.30 & 120.89 & -8.60 & -3.47 & -4.66 & $0.00^{*}$ & 5.87 & 1.18 & 132.04 & 3.54 & 8.19 & 4.99 & $0.00^{*}$ \\
\hline \multirow{2}{*}{ L6 } & 1 & -2.75 & 1.41 & 118.37 & -5.54 & 0.05 & -1.94 & 0.05 & 6.22 & 1.35 & 125.68 & 3.55 & 8.89 & 4.61 & $0.00^{*}$ \\
\hline & 2 & -3.35 & 1.34 & 124.27 & -6.00 & -0.70 & -2.50 & 0.01 & 5.88 & 1.22 & 130.43 & 3.47 & 8.29 & 4.82 & 0.00 \\
\hline \multirow{2}{*}{$\mathrm{L} 7$} & 1 & -9.80 & 3.34 & 77.55 & -16.44 & -3.15 & -2.93 & 0.00 & 5.75 & 2.10 & 84.92 & 1.57 & 9.93 & 2.74 & 0.01 \\
\hline & 2 & -0.62 & 3.56 & 88.49 & -7.69 & 6.45 & -0.17 & 0.86 & 5.15 & 1.91 & 88.67 & 1.36 & 8.95 & 2.70 & 0.01 \\
\hline
\end{tabular}

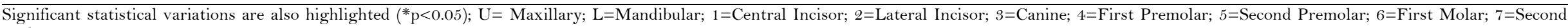
Molar. 
Table 4. Statistical comparisons for intercanine and intermolar width changes for both arches from pre- (To) to post-treatment values (T1).

\begin{tabular}{|c|c|c|c|c|c|c|c|c|c|}
\hline Variables & Group & Arch & Estimate & SE & Df & Lower. CL & Upper. CL & T. ratio & p-value \\
\hline \multirow[t]{4}{*}{ Intercanine Width (mm) } & 1 & Maxillary & -2.91 & 0.53 & 45.02 & -3.99 & -1.84 & -5.45 & $0.00^{*}$ \\
\hline & 2 & & -2.09 & 0.50 & 47.48 & -3.09 & -1.09 & -4.21 & $0.00^{*}$ \\
\hline & 1 & Mandibular & -1.33 & 0.50 & 50.35 & -2.35 & -0.32 & -2.65 & $0.01^{*}$ \\
\hline & 2 & & -1.05 & 0.45 & 50.99 & -1.96 & -0.15 & -2.33 & $0.02 *$ \\
\hline \multirow[t]{4}{*}{ Intermolar Width (mm) } & 1 & Maxillary & -2.40 & 0.67 & 48.19 & -3.74 & -1.07 & -3.61 & $0.00^{*}$ \\
\hline & 2 & & -2.54 & 0.63 & 52.26 & -3.80 & -1.29 & -4.06 & $0.00^{*}$ \\
\hline & 1 & Mandibular & -2.50 & 0.48 & 44.90 & -3.46 & -1.54 & -5.25 & $0.00^{*}$ \\
\hline & 2 & & -0.71 & 0.41 & 44.95 & -1.54 & 0.11 & -1.75 & 0.09 \\
\hline
\end{tabular}

Statistically significant differences are also indicated $\left(\mathrm{p}<0.05^{*}\right)$.

\section{Discussion}

Despite the introduction of clear aligners in orthodontics, the use of vestibular fixed appliances (FAs) is still broad all over the world. As a matter of fact, their use is indicated in those cases considered as difficult to manage with aligners such as extractive cases, severe deep bite and open bite cases [27], or whenever radicular movement is to achieve [28-30].

CLAs have a long history and, little by little, some improvements have been introduced, such as straight wire concept [31], subsequent different prescription proposed by different authors, manufacturing processes, reduced sizes and dimensions and so on [32].

The introduction of PSLAs in the late 90's, has stirred up the orthodontic scientific community claiming bone regeneration during expansion movements, reduced chair time, fewer appointments and months of therapy, less need for extractions, shorter treatment time, more biological forces with less friction, no anchorage loss and excessive proclination of mandibular incisors, less painful experience and accumulation of plaque [13,33]. Despite all these claims, the literature agreed that SLAs would have the only advantages of reducing chair time and preventing excessive proclination of mandibular incisors during alignment and levelling phases [13]. Nevertheless, PSLAs are attractive and they could be considered a good alternative for CLAs keeping in mind their higher costs.

This retrospective study aimed to compare PSLAs and CLAs effects during orthodontic therapy, investigating dental parameters (torque and tip) and transversal width variations using digital methods that are simpler and more predictable concerning analogical measures. Regarding the intermolar and intercanine width variations during the treatment, there is a general increase of these linear values in both arches and groups. It seems to be due to the expanding nature of these appliances, especially when broad arches are used [18]. The concomitant increase of torque values in lateral sectors clarifies that this expansion is principally due to vestibular tipping of the crowns rather than bodily movement, with a direct correlation of the two phenomena abovementioned. This finding is also in accordance with previous authors [22,34,35].

The evaluation of linear transverse dimensions at the end of treatment highlights a major increase of maxillary intercanine width with respect to mandibular one and these results agree with those of Basciftci et al. [36]; this trend is not detectable regarding intermolar width.

In the group treated with CLAs, the mandibular intermolar width does not register a marked expansion compared to the group treated with PSLAs and this is probably due to the difference in shape and size of the archwires used. As a matter of fact, Damon archwires are more expanded than UNAform archwires [37], and it could explain the major rate of increased torque observations in Group 1, although these do not 
reach a significant statistical difference when the two groups are compared, except for mandibular lateral incisors and mandibular first premolars.

Also, considering the above-mentioned two exceptions, it must be taken in mind that the torque values at the end of treatment are the same in the two groups and that the major expansion is probably lined to torque differences registered at To. These findings agree with previous reports, which did not find any difference between the two types of appliances [19,35], especially when broad archwires are used in CLAs [18]. The reduction of mandibular canine torque values in the CLAs during treatment seems to be due to different initial torque values for these teeth between the two groups rather than a different effect of the appliances used.

Regarding tip variations during the treatment, a specific trend is not detectable from $-6.21^{\circ}$ to $5.81^{\circ}$. However, it is possible to appreciate a tendency towards a reduction of tip values in the lateral sectors. Reduced tip values for the FAs in the posterior sectors of arches have been proposed by some authors in order both to counteract the tendency to proclination of mandibular incisor (tip back anchorage) [38] and to prevent side effects of Class II elastics and it is routinely used in some today's prescriptions [39]. On the other hand, it should keep in mind that the most of orthodontic cases needing treatment are characterized by Class II skeletal malocclusion with a natural tendency to mesial tipping of mandibular dento-alveolar component [40]; therefore, the use of FAs cause a reduction of tip values especially in the posterior sectors.

In general, both FAs investigated have an overall expansive potential with an augmentation of transverse dimensions for both arches. The principal mechanism is vestibular tipping of teeth rather than bodily translation. This effect allows to align and to solve crowding in an efficient way in non-extractive cases.

This study has some limitations. First of all, it is a retrospective study with no or poor possibility to supervise some possible methodological bias like partial inhomogeneity of the groups compared. Another limit is the reduced sample taken into consideration and, therefore, further randomized controlled trials should be performed in the future to overcome the abovementioned limitations.

\section{Conclusion}

The null hypothesis is partially accepted with no detectable differences regarding both angular measures (tip and torque values) and linear measures (intermolar and interpremolar width) between the CLAs and PSLAs. Torque values and transverse linear measures generally tend to increase during orthodontic treatment, allowing the resolution of misalignment and crowding in non-extractive treatments. On the other hand, a general trend is not detectable for tip values, although reducing the tip of lateral sectors is present for both appliances. The only differences detectable between the two groups are the mandibular intermolar width measure, with a minor expansive tendency of CLAs concerning PSLAs.

\section{Authors' Contributions}

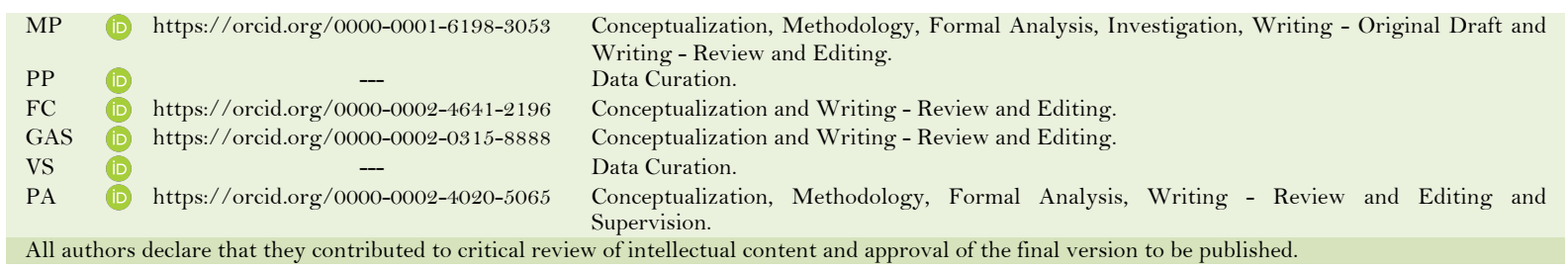

\section{Financial Support}

None. 


\section{Conflict of Interest}

The authors declare no conflicts of interest.

\section{Data Availability}

The data used to support the findings of this study can be made available upon request to the corresponding author.

\section{References}

[1] Harradine NW. Self-ligating brackets and treatment efficiency. Clin Orthod Res 2001; 4(4):220-7. https://doi.org/10.1034/j.1600-0544.2001.40406.x

[2] Arreghini A, Lombardo L, Mollica F, Siciliani G. Torque expression capacity of 0.018 and 0.022 bracket slots by changing archwire material and cross section. Prog Orthod 2014; 15(1):53.

https://doi.org/10.1186/s40510-014-0053-x

[3] Harradine N. The history and development of self-ligating brackets. Semin Orthod 2008; 14(1):5-18.

[4] Manfredini D, Stellini E, Gracco A, Lombardo L, Nardini LG, Siciliani G. Orthodontics is temporomandibular disorder-neutral. Angle Orthod 2016; 86(4):649-54. https://doi.org/10.2319/051015-318.1

[5] Lopez MA, Andreasi Bassi M, Confalone L, Gaudio RM, Lombardo L, Lauritano D. The influence of conical plus octagonal internal connection on implant survival and success rate: a retrospective study of 66 fixtures. J Biol Regul Homeost Agents 2016; 30(2 Suppl 1):49-54.

[6] Lopez MA, Andreasi Bassi M, Confalone L, Gaudio RM, Lombardo L, Lauritano D. Retrospective study on bonelevel and soft-tissue-level cylindrical implants. J Biol Regul Homeost Agents 2016; 30(2 Suppl 1):43-8.

[7] Lopez MA, Andreasi Bassi M, Confalone L, Gaudio RM, Lombardo L, Lauritano D. Clinical outcome of 215 transmucosal implants with a conical connection: a retrospective study after 5-year follow-up. J Biol Regul Homeost Agents 2016; 30(2 Suppl 1):55-60.

[8] Lombardo L, Stefanoni F, Mollica F, Laura A, Scuzzo G, Siciliani G. Three-dimensional finite-element analysis of a central lower incisor under labial and lingual loads. Prog Orthod 2012; 13(2):154-63. https://doi.org/10.1016/j.pio.2011.10.005.

[9] Di Fazio D, Lombardo L, Gracco A, D'Amico P, Siciliani G. Lip pressure at rest and during function in 2 groups of patients with different occlusions. Am J Orthod Dentofacial Orthop 2011; 139(1):e 1-e6.

[10] Lombardo L, Scuzzo G, Arreghini A, Gorgun O, Ortan YO, Siciliani G. 3D FEM comparison of lingual and labial orthodontics in en masse retraction. Prog Orthod 2014; 15(1):38. https://doi.org/10.1 186/s40510-014-0038-9

[11] Lombardo L, Ortan YÖ, Gorgun Ö, Panza C, Scuzzo G, Siciliani G. Changes in the oral environment after placement of lingual and labial orthodontic appliances. Prog Orthod 2013; 14:28. https://doi.org/10.1186/2196-1042-14-28

[12] Ehsani S, Mandich MA, El-Bialy TH, Flores-Mir C. Frictional resistance in self-ligating orthodontic brackets and conventionally ligated brackets. A systematic review. Angle Orthod 2009; 79(3):592-601. https://doi.org/10.2319/060208-288.1

[13] Chen SS, Greenlee GM, Kim JE, Smith CL, Huang GJ. Systematic review of self-ligating brackets. Am J Orthod Dentofacial Orthop 2010; 137(6):726.e1-726.e18; discussion 726-7. https://doi.org/10.1016/j.ajodo.2009.11.009

[14] Fleming PS, DiBiase AT, Sarri G, Lee RT. Comparison of mandibular arch changes during alignment and leveling with 2 preadjusted edgewise appliances. Am J Orthod Dentofacial Orthop 2009; 136(3):340-7. https://doi.org/10.1016/j.ajodo.2007.08.030

[15] Pandis N, Polychronopoulou A, Makou M, Eliades T. Mandibular dental arch changes associated with treatment of crowding using self-ligating and conventional brackets. Eur J Orthod 2010; 32(3):248-53. https://doi.org/10.1093/ejo/cjp123

[16] Arreghini A, Trigila S, Lombardo L, Siciliani G. Objective assessment of compliance with intra- and extraoral removable appliances. Angle Orthod 2017; 87(1):88-95. https://doi.org/10.2319/020616-104.1

[17] Anand M, Turpin DL, Jumani KS, Spiekerman CF, Huang GJ. Retrospective investigation of the effects and efficiency of self-ligating and conventional brackets. Am J Orthod Dentofacial Orthop 2015; 148(1):67-75. https://doi.org/10.1016/j.ajodo.2014.12.029

[18] Atik E, Akarsu-Guven B, Kocadereli I, Ciger S. Evaluation of maxillary arch dimensional and inclination changes with self-ligating and conventional brackets using broad archwires. Am J Orthod Dentofacial Orthop 2016; 149(6):830-7. https://doi.org/10.1016/j.ajodo.2015.11.024

[19] Shook C, Kim SM, Burnheimer J. Maxillary arch width and buccal corridor changes with Damon and conventional brackets: A retrospective analysis. Angle Orthod 2016; 86(4):655-60. https://doi.org/10.2319/050515-304.1

[20] Odegaard J, Meling T, Meling E. An evaluation of the torsional moments developed in orthodontic applications. An in vitro study. Am J Orthod Dentofacial Orthop 1994; 105(4):392-400.

https://doi.org/10.1016/So889-5406(94)70134-2 
[21] Sebanc J, Brantley WA, Pincsak JJ, Conover JP. Variability of effective root torque as a function of edge bevel on orthodontic arch wires. Am J Orthod 1984; 86(1):43-51. https://doi.org/10.1016/0002-9416(84)90275-6

[22] Lineberger MB, Franchi L, Cevidanes LH, Huanca Ghislanzoni LT, McNamara JA Jr. Three-dimensional digital cast analysis of the effects produced by a passive self-ligating system. Eur J Orthod 2016; 38(6):609-14. https://doi.org/10.1093/ejo/cjv089

[23] Andrews L. The Straight Wire Appliance: Syllabus of Philosophy and Techniques. 2nd ed. San Diego: Foundation of Orthodontic Education and Research; 1975.

[24] Huanca Ghislanzoni LT, Lineberger M, Cevidanes LH, Mapelli A, Sforza C, McNamara JA Jr. Evaluation of tip and torque on virtual study models: a validation study. Prog Orthod 2013; 14:19.

https://doi.org/10.1186/2196-1042-14-19

[25] Dahlberg G. Statistical Methods for Medical and Biological Students. New York: Interscience Publications; 1940.

[26] Sawilowsky SS. New Effect Size Rules of Thumb. J Mod Appl Stat Methods 2009; 8(2):26.

[27] Pisani L, Bonaccorso L, Fastuca R, Spena R, Lombardo L, Caprioglio A. Systematic review for orthodontic and orthopedic treatments for anterior open bite in the mixed dentition. Prog Orthod 2016; 17(1):28. https://doi.org/10.1186/s405 10-016-0142-0

[28] Lombardo L, Palone M, Carlucci A, Siciliani G. Clear aligner hybrid approach: A case report. J World Fed Orthod 2020; 9(1):32-43. https://doi.org/10.1016/j.ejwf.2020.01.001

[29] Lombardo L, Carinci F, Martini M, Gemmati D, Nardone M, Siciliani G. Quantitive evaluation of dentin sialoprotein (DSP) using microbeads - a potential early marker of root resorption. Oral Implantol 2016; 9(3):132-42. https://doi.org/10.11138/orl/2016.9.3.132

[30] Lombardo L, Toni G, Stefanoni F, Mollica F, Guarneri MP, Siciliani G. The effect of temperature on the mechanical behavior of nickel-titanium orthodontic initial archwires. Angle Orthod 2013; 83(2):298-305. https://doi.org/10.2319/040612-287.1

[31] Andrews LF. The straight-wire appliance. Explained and compared. J Clin Orthod 1976; 10(3):174-95.

[32] Palone M, Spedicato GA, Lombardo L. Analysis of tooth anatomy in adults with ideal occlusion: A preliminary study. Am J Orthod Dentofacial Orthop 2020; 157(2):2 18-27. https://doi.org/10.1016/j.ajodo.2019.03.024

[33] Perrini F, Lombardo L, Arreghini A, Medori S, Siciliani G. Caries prevention during orthodontic treatment: In-vivo assessment of high-fluoride varnish to prevent white spot lesions. Am J Orthod Dentofacial Orthop 2016; 149(2):23843. https://doi.org/10.1016/j.ajodo.2015.07.039

[34] Lucchese A, Manuelli M, Albertini P, Ghislanzoni LH. Transverse and torque dental changes after passive selfligating fixed therapy: A two-year follow-up study. Am J Orthod Dentofacial Orthop 2019; 156(1):94-103. https://doi.org/10.1016/j.ajodo.2018.08.019

[35] Almeida MR, Futagami C, Conti AC, Oltramari-Navarro PV, Navarro Rde L. Dentoalveolar mandibular changes with self-ligating versus conventional bracket systems: A CBCT and dental cast study. Dental Press J Orthod 2015; 20(3):50-7. https://doi.org/10.1590/2176-9451.20.3.050-057.oar

[36] Basciftci FA, Akin M, Ileri Z, Bayram S. Long-term stability of dentoalveolar, skeletal, and soft tissue changes after non-extraction treatment with a self-ligating system. Korean J Orthod 2014; 44(3):119-27. https://doi.org/10.4041/kjod.2014.44.3.119

[37] Lombardo L, Coppola P, Siciliani G. Comparison of dental and alveolar arch forms between different ethnic groups. Int Orthod 2015; 13(4):462-88. https://doi.org/10.1016/j.ortho.2015.09.013

[38] McLaughlin RP, Bennett JC. Evolution of treatment mechanics and contemporary appliance design in orthodontics: A 40-year perspective. Am J Orthod Dentofacial Orthop 2015; 147(6):654-62. https://doi.org/10.1016/j.ajodo.2015.03.012

[39] Janson G, Sathler R, Fernandes TM, Branco NC, Freitas MR. Correction of Class II malocclusion with Class II elastics: a systematic review. Am J Orthod Dentofacial Orthop 2013; 143(3):383-92. https://doi.org/10.1016/j.ajodo.2012.10.015

[40] McNamara JA Jr. Components of class II malocclusion in children 8-10 years of age. Angle Orthod 1981; 51(3):177202. 